\title{
28 Research Soure \\ Efficacy and safety of capsule endoscopy in octogenarian and elderly patients: A retrospective study
}

\author{
Alessandro Pezzoli \\ University Hospital Ferrara \\ Matteo Guarino ( $\nabla$ grnmtt@unife.it ) \\ University Hospital Ferrara \\ Nadia Fusetti \\ University Hospital Ferrara \\ Elena Pizzo \\ University College London \\ Marzia Simoni \\ University of Pisa \\ Loredana Simone \\ University Hospital Ferrara \\ Viviana Cifalà \\ University Hospital Ferrara \\ Riccardo Solimando \\ University Hospital Ferrara \\ Giacomo Caio \\ University Hospital Ferrara \\ Roberto De Giorgio \\ University Hospital Ferrara \\ Alberto Merighi \\ University Hospital Ferrara
}

\section{Research Article}

Keywords: Capsule endoscopy, octogenarians, occult gastrointestinal bleeding, capsule aspiration

Posted Date: June 29th, 2021

DOl: https://doi.org/10.21203/rs.3.rs-668519/v1 
License: (c) (i) This work is licensed under a Creative Commons Attribution 4.0 International License. Read Full License 


\section{Abstract \\ Background}

Life expectancy and the number of ultra-octogenarians increased significantly, thus making crucial the appropriateness of several endoscopic procedures in elderly patients. The aim of our study was to provide a retrospective analysis of the efficacy and safety of capsule endoscopy in patients aged over 80 years.

\section{Patients and Methods}

In this single-centre study, 900 patients underwent capsule endoscopy between 2002 and 2015 for different indications; of these 106 patients aged $\geq 80$ years (group A) and 99 patients aged $40-60$ years (control group B) were randomly selected.

\section{Results}

Occult gastrointestinal bleeding accounted for $62.1 \%$ of all indications for capsule endoscopy in group B, compared to $95.2 \%$ in group $A(p<0.001)$. Although not statistically significant, the diagnostic yield was higher in group $A(71 \%) v s$. group $B(62 \%)$. The percentages of reaching the cecum and the median gastric transit time were uniform within the two groups. In contrast, small bowel transit time was longer in group A vs. B. Small bowel preparation was similar in the two groups. The exam was generally well tolerated in both groups, with capsule aspiration being one of the main adverse events, which occurred in two elderly patients.

\section{Conclusions}

Our data expand previous findings confirming that capsule endoscopy can be performed safely even in very old patients and show that the diagnostic yield is similar to that of younger patients.

\section{Introduction}

Over the past century, a remarkable change in population demographics has been observed worldwide. Life expectancy has increased and the number of subjects considered old (> 65 years) has been estimated to increase from 900 million to two billions by 2050. Currently 125 million people are aged over 80 years [1] and the number is expected to increase. Among the European countries, Italy and Germany have the oldest population with $19 \%$ of the inhabitants over 65 years and $5 \%$ over 80 [2]. These demographic changes have an impact not only on society but also on health policies. For example, in 2006 the American Society of Gastrointestinal Endoscopy (ASGE) has published a guideline on the 
appropriate use of endoscopy in geriatric patients [3] and the appropriateness and safety of several endoscopic procedures have been investigated in ultra-octogenarians [4-5].

Capsule endoscopy (CE), approved in 2000 by the Food and Drug Administration, has seen a rapid increase in its use because of major diagnostic advantages over other techniques (i.e. radiology) [6]. However, few studies have explored the efficacy and safety of capsule endoscopy in octogenarians [7-9]. In this study, we analysed retrospectively the diagnostic yield, safety, spectrum of small bowel diseases, intestinal transit time, the success rate in reaching the cecum of $C E$ and the bowel preparation in a group of patients over 80 years compared to those between 40 to 60 years.

\section{Patients And Methods}

This is a single-centre, retrospective study carried out at the Department of Gastroenterology of the University Hospital in Ferrara (Italy), where more than 900 patients underwent CE between 2002 and 2015. Of these 900 patients we randomly selected and extracted the data of 106 patients over 80 years (group A) and 99 patients between $40-60$ years (control group B). While initially all patients undergoing CE were hospitalized, since 2009 the majority were outpatients. Despite the CE's manufacturer suggests only one overnight fasting before the procedure, most patients $(>90 \%)$ ingested two litres of polyethylene glycol (PEG) solution the day before. In group A, 4 patients did not receive bowel preparation vs. 12 patients in group $B(p=0.06 ;$ n.s.). No prokinetics drugs or simethicone were administered before the ingestion of the CE. About $80 \%$ of the procedures were performed using the Pillcam SB® (Given Imaging Israel System; software Rapid v 6.5, Pillcam SB2) and 20\% using the MiroCam $\AA$, Intromedic Company, South Korea system. The two types of capsule were distributed as follows: group A, 75 cases were performed using Pillcam and 31 with MiroCam vs. group B, 80 cases with Pillcam and 19 with MiroCam. The batteries of these capsules last 8 hours and 12 hours, respectively. All patients provided a written informed consent before undergoing CE. The intestinal cleanliness was graded according to a 3-point scale [10]: 0 , if no bubbles and/or dark fluid were found; 1 , if bubbles and/or dark fluid partly obscured the view; and 2, if bubbles and/or dark fluid obscured the view. We retrospectively reviewed the CE reports and collected data on the diagnostic yield, findings, gastric transit time (GTT), small bowel transit time (SBTT) (using the reader's timer), rate of success in reaching the cecum and complications reported in each group. Finally, the level of bowel cleanliness was compared in the two groups. The GTT was defined as the time elapsed between the first gastric image and the first duodenal image. The SBTT was defined as the time elapsed between the first duodenal image and the first cecal image. We excluded from the analysis of SBTT those patients in whom the capsule did not reached the cecum. Significant findings were considered all lesions found in the small bowel that can explain the patient's symptoms or abnormal findings. All CEs procedures were independently reviewed by two of the authors (A.P. and N.F.) who have a long experience in CE evaluation and interpretation (> 400 CE performed). From 2006, all CE findings were labeled using the Capsule Endoscopy Structured Terminology classification [11].

\section{Statistical analysis}


Statistical analyses were performed using the Statistical package for the Social Sciences (SPSS) rel.13.0. The following analyses were performed: frequency distribution; contingency tables with chi-square test to evaluate the difference between the two age groups (for categorical variables, i.e. indication to CE and diagnostic yield); Kolmogorov-Smirnov non-parametric test for the goodness of fit to test the distribution of the transit times; Mann-Whitney non parametric-test to assess the difference in GTT (not normally distributed, and log-10 transformed for the graphic representation) in both groups; the one-way analysis of variance (ANOVA) to test the difference of SBTT (normally distributed) between the age groups. Finally, to evaluate the difference between age groups concerning the different categories of indication to CE and diagnostic yield, we performed pairwise comparisons of proportions by using the Primer of Biostatistics (7th edition). Statistical significance was set at $p<0.05$.

\section{Results}

\section{Patients' characteristics and indications for CE}

In total, 205 patients were included in the study. Overall, the mean age was $67.8 \pm 17.4$ years (range 40-94 years, median 80 years) and 114 of them were males (55.6\%). In group A (106 patients) the mean age was $83.8 \pm 3.2$ vs. $50.7 \pm 6.4$ years in group $B$ (99 patients). No significant difference in gender was observed (50.9\% males in group A vs. $60.6 \%$ in group B). Patients affected by diabetes were 15 in group A $(14 \%)$ and $10(14 \%)$ in group B. Generally, the primary indication for CE was obscure gastrointestinal intestinal bleeding (OGIB) in 158 cases (77\%), of which $18 \%$ of overt type. Suspected Crohn's disease was one of the most frequent indications for CE (8 cases, $3.9 \%$ of the total). In 39 cases the primary indication to CE was: hematochezia (12 cases, $5.9 \%$ ), abdominal pain (8 cases, $3.9 \%)$, unexplained diarrhea (7 cases, $3.5 \%$ ), polyposis syndrome (Gardener, Peutz-Jeghers and familial adenomatous polyposis) in 6 cases (2.9\%); in 6 cases the indication was missing (2.9\% of the study group) and we excluded these patients from the final analysis. The primary indication for $\mathrm{CE}$ significantly differed between the two age groups $(p<0.001)$. In details, OGIB accounted for $62.1 \%$ of indication for CE in group B (40 cases obscure bleeding, $42.1 \%$, and 19 overt type, $20 \%)$ compared to $95.2 \%$ in group $A(p<0.001)$, with 81 cases of OGIB (77.9\%) and 18 overt type (17.3\%). The 8 cases of suspected Crohn's disease were all in group B, likewise the miscellanea of minor indications for CE with exception for hematochezia (7 in group B vs. 5 in A). Data are summarized in Table 1.

\section{Diagnostic yield and findings}

Overall, we found positive findings in 131 cases with a diagnostic yield of $63.9 \%$. Although not statistically significant, the diagnostic yield was higher in group A (71\%) than in B (62\%). Angiectasias (Figure 1 ) were the most common finding (22.4\% of the total) and were statistically more frequent in the aged group than in the younger one (group A, $34.3 \%$ vs. $11.6 \%$ in $B ; p<0.001$ ). Ulcers/erosions were the second more frequent finding ( $18 \%$ of the total), and their prevalence did not differ significantly between group A (22\%) and B (16\%). Endoscopic features suggestive of Crohn's disease (Figure 2) were present in 
only one patient in group A vs. 6 patients in B. Two small bowel tumors (1 adenocarcinoma e 1 lymphoma) were diagnosed in the group B. The other findings (miscellanea of aspecific intestinal inflammation, lipomas, hypertensive enteropathy and ischemic enteropathy) were statistically more frequent in the younger group. Data are summarized in Table 2.

\section{Completeness of CE and intestinal transit time}

CE reached the cecum in 149 patients $(72.7 \%)$. There was no difference within the two age groups in terms of success in reaching the cecum (77 cases, $72.6 \%$ in group A vs. 72 cases, $72.7 \%$ in B). The median value of GTT (not normally distributed) was 20 minutes $\left(25^{\text {th }}-75^{\text {th }}\right.$ percentiles $\left.10-55\right)$ and did not significantly differ between the two age groups (18 min in group A vs. $23 \mathrm{~min}$ in B) (see Fig. 3). The mean value of SBTT (normally distributed) was $293 \pm 115 \mathrm{~min}$ (median $278 \mathrm{~min}, 25^{\text {th }}-75^{\text {th }}$ percentiles $218-360$ ). Conversely to GTT, SBTT was significantly longer in group A than in group B (mean $312 \pm 122$ min vs. 42 \pm 72 min, respectively, $p=0.04$ by ANOVA) (see Fig. 4). Data are summarized in Fig. 3 and 4 .

\section{Intestinal cleanliness and complications}

Small bowel cleanliness was similar in both groups; globally $74.2 \%$ of the study group had a grade score 0 to 1 . We did not observe any case of capsule retention, but two cases of capsule aspiration (1.8\%) in the bronchial system [12] occurred in the aged group. One patient aged 86 years was not able to swallow the capsule. Finally, 3 patients in group A had a cardiac pacemaker; this condition is a relative contraindication to $\mathrm{CE}$, but according to recent evidence we performed the $\mathrm{CE}$ procedure and no complications occurred [13-14].

\section{Discussion}

Our data expand previous experiences and confirm that CE can be performed safely even in very old patients. Moreover, our study showed that the diagnostic yield is similar, although not statistically significant, to that of younger subjects. We did not find any difference in terms of completeness of bowel preparation score for CE. In our study, OGIB is the main indication to CE in aged group confirming the results of similar studies [7-8]. The finding of CE performed in elderly patients can be explained by epidemiological factors showing that bleeding-related anemia in subject older than 80 years reaches an incidence of 350 cases per 100.000 person / year [15]. Furthermore, in $5 \%$ of cases the cause of bleeding was not identified and this percentage increases to $15-20 \%$ in elderly patients [16]. The second most common indication to $C E$ is the suspect of an underlying Crohn's disease [17]. As expected, this diagnosis has been established in group B since this disease is more common in young people, confirming the result reported by Papadopulos et al. [18]. However, the diagnostic yield did not significantly differ between older and younger patients, according to Girelli et al., who compared patients $\geq 80$ years old with 
those younger than 80 years [7]. In the study of Gomez et al. [8], the diagnostic yield was higher in the group of patients aged $>80$ years $(73 \%$ vs. $53 \%)$. This trend was confirmed in previous studies [19-21] in which the increasing age positively correlated with a diagnostic yield of CE mainly due to the higher incidence of angiodysplasias in elderly patients. Indeed, similarly to other authors [8, 9, 17], we found that angiectasias was the most common finding, more prevalent in older than younger patients. The increasing incidence of vascular abnormalities in the intestinal wall with age is a well known phenomenon and these lesions are responsible for a significant portion of intestinal bleeding in older patients [22, 23]. A high production and release of angiogenic factors has been reported to occur with increasing age, and this feature can play a role in angiectasias [24].

As expected, all cases of Crohn's disease have been found in group B, but due to the small number of cases we did not find any statistically significant difference between the two groups. Small bowel tumors are rare [25], indeed we detected only two cases (1\% of all study group) in the young group. This prevalence is similar to that reported in a multicenter study involving 5129 patients undergoing CE (on average $2.4 \%$, but varies between $0.75 \%$ and $9.3 \%$ ). However, neoplastic lesions may present with obscure gastrointestinal bleeding even in young patients as reported by Koulauzidis et al. [26], a finding not confirmed by others $[7,8]$. In our study, ulcers and erosions were similar in the two groups although more prevalent in the aged group. We do not have information about the patients' consumption of nonsteroidal anti-inflammatory drugs (NSAID), including low-dose aspirin. Nonetheless, it is worth mentioning that the $21 \%$ of inflammatory lesions found in group $A$ is similar to the percentage detected in healthy subjects undergoing $C E[27,28]$. Other findings were significantly more prevalent in group $B$, probably because the miscellanea of minor indications for CE was mainly observed in this group.

As in other studies $[8,9,18]$, we found no difference between the two groups on the number of CEs that reached the cecum. In the study by Girelli et al. [7] the elderly patients presented a lower rate of completion of CE ( $74 \%$ vs. $89 \%)$, which was attributed to a high number of elderly patients affected by non-specific abnormalities of esophageal and gastric motility. The overall percentage of $72.7 \%$ of CE reaching the cecum found in our study is slightly lower compared to that found in other studies (from 77 to $100 \%)[8,9,18,20]$. A possible explanation could be that the use of CE in early years of this procedure was performed mainly to inpatients requiring bed rest, a condition likely impairing the rate of completed CE. Moreover, we do not use routinely prokinetic drugs before swallowing CE (in contrast to $16 \%$ of patients enrolled by Girelli et al.). However, there is no doubt that the completion of CE is a crucial point in achieving a good diagnostic yield and that increasing efforts should be made to optimize a complex and expansive procedure such CE. Similarly to previous studies, we did not find significant differences in the GTT between the two groups, whereas, compared to other studies, we showed a longer SBTT. Age-related neurodegenerative abnormalities in the enteric nervous system have been observed in some animal models [29] and these changes can explain the slower SBTT in elderly patients. The presence of blood in the gut lumen is known to exert a cathartic effect that decreases the intestinal transit time [30]. Moreover, half of the patients in the Papadopulos et al.'s study received sodium phosphate as bowel preparation, which accelerates CE transit through the ileum [31]. However, we observed that a delayed SBTT did not 
influence the rate of completeness of CE examination. The technological improvement of new longactivity batteries allowed us to register the whole SBTT.

We found that the level of bowel preparation in the two groups was similar. The evidence in the literature on this topic is controversial; Tsibouris et al. showed that the level of bowel preparation was worst in the aged group [9], while Papadopulos et al. demonstrated a borderline significant trend for poor bowel preparation in patients over 64 vs. under 40 and 40-64-year-old patients [18]. Gomez, conversely, did not find statistically significant difference between patients aged $\geq 80$ and those $<80$ years of age [8]. These discordant results could be due to the different doses / volume / type of agents used for the bowel preparation (e.g., PEG $2 \mathrm{~L}$ or $4 \mathrm{~L}$ or $\mathrm{NaP}$ ) or even the absence of bowel preparation (early years of CE). Nowadays, bowel preparation before CE is recommended because it increases the diagnostic yield [32, 33].

Complications were very rare; no case of capsule retention was observed in the two groups. The reported capsule retention rate is about 1\% [34], although in some studies including patients with Crohn's disease the percentage increases to 7\% [35]. Only 8 patients underwent CE for suspected Crohn's disease. In addition, we made a strict selection of the patients who could perform CE (many of them underwent radiological procedures or patency capsule in order to exclude the presence of stenosis), thus preventing the capsule retention. Similarly, in Tsibouris et al.'s study no cases of capsule retention was observed in the two groups. Gomez et al, in their large sample size ( 195 patients age $>80$ years and 585 patients $<80$ years old) study, observed 2 cases of capsule retention in the aged group and 5 in the control group, but the difference was not statistically significant (1.03\% vs. 0.85\%) [8]. Unexpectedly, we observed two cases of capsule tracheal aspiration, both episodes occurred in patients over 80 years. Airway aspiration of the $\mathrm{CE}$ is a very rare complication; only few cases were described in literature and all of them occurred in elderly patients (two cases in 90-year-old and one in a 93-year-old patient) [12,36-42] thus confirming that this complication is typical of geriatric population even with no history of swallowing disorders. Although the aspiration of capsule endoscope is a potentially life threatening complication, it does not cause significant symptoms in the majority of patients and sometimes can resolve spontaneously [12, 41-42]. In our cohort one patient in group A was not able to swallow the capsule. Similar results were reported in the study by Girelli et al. [7].

Our study emphasizes the role of CE even in very old patients were the diagnostic yield is similar compared to younger subjects. Since we did not find differences in term of completeness, bowel preparation and diagnostic yield there are no reasons to avoid this procedure in octogenarians that represent a growing portion of our patients. The main strength of our study is that the age of the control group (patients $<60$ years) is less than 65 years, the conventional cut-off age for ageing. Clearly, we acknowledge some limitations of our study, including a single-center, retrospective design; the lack of data on comorbidities; no data on drugs (in particular NSAIDs) that are known to affect the results of CE; absence of follow-up information to understand whether CE results had an impact on the patients' outcome in both groups. 


\section{Conclusions}

Ageing inevitably leads to the occurrence of multiple chronic conditions, including patients with various GI diseases. In this study, we confirmed that CE represents an important diagnostic tool even in a subset of elderly (> 80 years) patients in whom the diagnostic yield is similar or increased compared to younger subjects. Indeed, Robertson et al. confirmed these data and provided evidence that CE is a safe procedure in this frail group of patients who may benefit of an examination disclosing sites of OGIBs [43]. Angiodysplasias are the most common finding in these patients. Although CE is generally safe capsule aspiration may occur in elderly patients even in absence of any risk factors.

\section{Abbreviations}

CE

Capsule endoscopy

ASGE

American Society of Gastrointestinal Endoscopy

PEG

polyethylene glycol

GTT

gastric transit time

SBTT

small bowel transit time

SPSS

Statistical package for the Social Sciences

ANOVA

one-way analysis of variance

OGIB

obscure gastrointestinal intestinal bleeding

FAP

familiar adenomatous polyposis

NSAID

non-steroidal anti-inflammatory drugs

$\mathrm{NaP}$

sodium phosphate

\section{Declarations}

Ethics approval and consent to participate: the study was carried out according to the principles of declaration of Helsinki. However, as a retrospective study, not actively involving patients, ethics committee approval was deemed unnecessary. 
Consent for publication: all patients provided a written informed consent before undergoing CE. Since the retrospective design of the study no formal consent to participate to the study was requested.

Availability of data and material: the datasets used and/or analysed during the current study are available from the corresponding author on reasonable request.

Competing interests: The authors declare no competing interests

Funding: None. Elena Pizzo was (in part) supported by the National Institute for Health Research (NIHR) Collaboration for Leadership in Applied Health Research and Care (CLAHRC) North Thames at Bart's Health NHS Trust. The views expressed are those of the author(s) and not necessarily those of the NHS, the NIHR or the Department of Health and Social Care.

\section{Authors' contributions:}

AP designed of the study, analysed the data and drafted the article; NF collected and analysed the data; EP revised the English version of the manuscript and interpreted the data; MS statistically analysed of the data; VC, LS, GC analysed the data; MG e RdG critically reviewed the manuscript; AM gave the final approval of the article.

Conflict of interest: All authors listed above do not have any financial and personal relationships with other people or organizations that could inappropriate influence their work.

\section{References}

1. World Health Organization, Ageing and health Fact. Sheet N404 September 2015.

2. Sanderson WC, Scherbov S. Measuring the speed of aging across population subgroups. PLoS One 2014; 9:e96289.

3. Qureshi W, Zuckerman MJ, Adler DG, Davila RE, Egan JV, Gan SI, Lichtenstein DR, Rajan E, Shen B, Fanelli RD, Van Guilder T, Baron TH, Standards of Practice Committee, American Society for Gastrointestinal Endoscopy. ASGE guidelines: modifications in endoscopic practice for the elderly. Gastrointest Endosc 2006; 63:566-569. 
4. Lagares-Garcia J.A, Kurek S., Collier B. Diaz F, Schilli E, Richey J, Moore RA. Colonoscopy in octogenarians and older patients. Surg Endosc 2001; 15: 262-265.

5. Sugiyama M, Atomi y. Endoscopic sphincterotomy for bile ducts stones in patients 90 years of age and older. Gastrointest Endosc 2000: 52:187-191.

6. Sidhu R, Sanders DS, McAlindon ME. Gastrointestinal capsule endoscopy: from tertiary centres to primary care. BMJ 2006; 332:528-531.

7. Girelli CM, Maiero S, Porta P, Canizzaro R. Small bowel capsule endoscopy performance in octogenarians: a case-control study. J Gerontol A Biol Sci Med Sci 2011; 66:68-73.

8. Gomez V, Cheesman A.R, Heckman M.G, Rawal B, Stark M.E, Lukens F.J. Safety of capsule endoscopy in the octogenarian as compared with younger patients. Gastrointest Endosc 2013;78: 744-749.

9. Tsibouris P, Kalantziz C, Apostolopoulos P, Alexandrakis G, Mavrogianni P, Kalantzis N Capsule endoscopy findings in patients with occult or overt bleeding older than 80 years. Dig Endosc 2012; 24:154-158.

10. de Franchis R, Avgerinos A, Barkin J, Cave D, Filoche B, ICCE. ICCE consensus for bowel preparation and prokinetics. Endoscopy 2005; 37: 1040-1045.

11. Korman LY, Delvaux M, Gay G, Haghenmuller F, Keuchel M, Friedman S, Weinstein M, Shetzline M, Cave D, De Franchis R. Capsule Endoscopy Structured Terminology (CEST): proposal of a standardized and structured terminology for reporting capsule endoscopy procedures. Endoscopy 2005; 37:951-959.

12. Pezzoli A, Fusetti N, Carella A, Gullini S. Asymptomatic bronchial aspiration and prolonged retention of a capsule endoscope: a case report. J Med Case Rep 2011; 5:341.

13. Leighton JA, Sharma VK, Srivathsan K, Heigh RI, McWane TL, Post JK, Robinson SR, Bazzell JL, Fleischer DE. Safety of capsule endoscopy in patients with pacemakers. Gastrointest Endosc 2004; 59:567-569.

14. Bandorski D, Bogossian H, Hoeltgen R. Capsule endoscopy is safe in patients with cardiac pacemakers and implantable cardioverter defibrillators. Dig Endosc 2015; 27:397.

15. Lanas A, García-Rodríguez LA, Polo-Tomás M, Ponce M, Alonso-Abreu I, Perez-Aisa MA, Perez-Gisbert J, Bujanda L, Castro M, Muñoz M, Rodrigo L, Calvet X, Del-Pino D, Garcia S. Time trends and impact of upper and lower gastrointestinal bleeding and perforation in clinical practice. Am J Gastroenterol 2009; 104: 1633-1641.

16. American Gastroenterological. Association medical position statement: evaluation and management of occult and obscure gastrointestinal bleeding. Gastroenterology 2000; 118: 197-200.

17. Liao Z, Gao R, Xu C, Li ZS. Indications and detection, completion, and retention rates of small-bowell capsule endoscopy: A systematic review. Gastrointest Endosc 2010; 71:280-286.

18. Papadopoulos AA, Triantafyllou K, Kalantzis C, Adamopoulos A, Ladas D, Kalli T, Apostolopoulos P, Kalantzis N, Ladas SD. Effects of ageing on small bowel video-capsule endoscopy examination. Am J Gastroenterol 2008; 103:2474-2480.

Page $11 / 17$ 
19. Zhang BL, Fang YH, Chen CX, Li YM, Xiang Z. Single-center experience of 309 consecutive patients with obscure gastrointestinal bleeding. World J Gastroenterol 2009; 7:5740-5745.

20. Ugresi R, Cianci R, Pagliari D, Newton E, Rizzo G, Costamagna G, Riccioni ME. Is capsule endoscopy appropriate for elderly patients? The influence of ageing on findings and diagnostic yield: An Italian retrospective study. Dig Liv Dis 2015: 47; 1086-1088.

21. Li L, Chen C, Li Y, Zang B. The role of caspule endoscopy in the diagnosis and treatment of obscure gastrointestinal bleeding in older individuals. Eur J Gastroenterol Hepatol 2016: 28;1425-1430.

22. Muhammad A, Pitchumoni CS. Evaluation of iron deficiency anemia in older adults: the role of wireless capsule endoscopy. J Clin Gastroentero/ 2009; 43: 627-631.

23. Shyung LR, Lin S, Chang WH, Wang HY, Chu CH, Wang TE, Chu CH, Wang TE, Shih SC. Capsule endoscopy in elderly patients with obscure gastrointestinal bleeding: retrospective analysis of 152 cases. Int J Gerontol 2010; 4:23-27.

24. Junquera F, Saperas E, de Torres I, Vidal MT, Malagelada JR. Increased expression of angiogenic factors in human colonic angiodysplasia. Am J Gastroenterol 1999; 194: 1070-1076.

25. Rondonotti E, Pennazio M, Toth E, Menchen P, Riccioni ME, De Palma GD, Scotto F, De Looze D, Pachofsky T, Tacheci I, Havelund T, Couto G, Trifan A, Kofokotsios A, Cannizzaro R, Perez-Quadrado E, De Franchis R, European Capsule Endoscopy Group; Italian Club for Capsule Endoscopy (CICE); Iberian Group for Capsule Endoscopy et al Small-bowel neoplasms in patients undergoing video capsule endoscopy: a multicenter European study. Endoscopy 2008; 40:488-495.

26. Koulaouzidis A, Yung DE, Lam JHP, Smirnidis A, Douglas S, Plevris JN. The use of small-bowel capsuleendoscopy in iron-deficiency anemia alone; be aware of the young anemic patient. Scand $J$ Gastroenterol 2012; 47:1094-100.

27. Endo H, Hosono K, Inamori M. Incidence of small bowel injury induced by low-dose aspirin: a crossover study using capsule endoscopy in healthy volunteers. Digestion 2009; 79:44-51

28. Goldstein JL, Lewis B, Zlotnick S, Geffen D. Celecoxib is associated with fewer small bowel lesions than naproxen + omeprazole in healthy subjects as determined by capsule endoscopy. $A m \mathrm{~J}$ Gastroenterol 2003; 98:297.

29. Wade PR. Aging and neural control of the GI tract. Age related changes in the enteric nervous system. Am J Physiol Gastrointest Liver Physiol 2002; 283:489-495.

30. Chaudhry V, Hyser MJ, Gracias VH, Gau FC. Colonoscopy: the initial test for acute lower gastrointestinal bleeding. Am Surg 1998; 64:723-728.

31. Spada C, Riccioni ME, Hassan C, Petruzziello L, Cesaro P, Costamagna G. PillCam colon capsule endoscopy: a prospective, randomized trial comparing two regimens of preparation. J Clin Gastroenterol 2011; 45:119-124.

32. Rokkas T, Papaxoinis K, Triantafyllou K, Pistiolas D, Ladas SD. Does purgative preparation influence the diagnostic yield of small bowel video capsule endoscopy? a meta-analysis. Am J Gastroenterol 2009:104;219-227. 
33. Song HJ, Moon JS, Shim KN. Optimal bowel preparation for video capsule endoscopy. Gastroenterol Res Pract 2016; 2016:6802810.

34. Karagiannis S, Faiss S, Mavrogiannis C. Capsule retention: a feared complication of wireless capsule endoscopy. Scand J Gastroentero/ 2009; 44:1158-1165.

35. Buchman AL, Miller FH, Wallin A, Chowdhry AA, Ahn C. Videocapsule endoscopy versus barium contrast studies for the diagnosis of Crohn's disease recurrence involving the small intestine. $A m \mathrm{~J}$ Gastroenterol 2004; 99:2171-2177.

36. Tabib S, Fuller C, Daniels J, Lo SK. Asymptomatic aspiration of a capsule endoscope. Gastrointest Endosc 2004; 60:845-847.

37. Sinn I, Neef B, Andus T. Aspiration of a capsule endoscope. Gastrointest Endosc 2004; 59:926-927.

38. Buchkremer F, Herrmann T, Stremmel W. Mild respiratory distress after capsule endoscopy. Gut 2004; 53:472.

39. Shiff A, Leighton JA, Heigh RI. Pulmonary aspiration of a capsule endoscope. Am J Gastroenterol 2007; 102:215-216.

40. Nathan SR, Biernat L. Aspiration-an important complication of small-bowel video capsule endoscopy. Endoscopy 2007; 39(Suppl 1):E343.

41. Guy T, Jouneau S, D'Halluin PN, Lena H. Asymptomatic bronchial aspiration of a video capsule. Interact Cardiovasc Thorac Surg 2009; 8:568-570.

42. Leeds JS, Chew TS, Sidhu R, Elliot CA, Sanders DS, McAlindon ME. Asymptomatic bronchial aspiration and retention of a capsule endoscope. Gastrointest Endosc 2009; 69:561.

43. Robertson A, Young D, Plevris J, Koulaouzidis A. PWE-101 capsule endoscopy in octogenarians. Gut 2018; 67:A168.

\section{Tables}

Table 1. Demographic and clinical features of the investigated patients subdivided by age in the two study groups.

\begin{tabular}{|c|c|c|c|c|}
\hline & $\begin{array}{c}\text { Total } \\
(\mathrm{n}=205) \\
\mathrm{n}(\%)\end{array}$ & $\begin{array}{c}\text { Group } A \\
(\geq 80 \text { yrs, } n=106) \\
n \text { (valid } \%)\end{array}$ & $\begin{array}{c}\text { Group B } \\
\text { (40-60 yrs, n=99) } \\
\text { n (valid \%) }\end{array}$ & $p$ \\
\hline Male gender & $114(55.6)$ & $54(50.9)$ & $60(60.6)$ & ns \\
\hline $\begin{array}{l}\text { Mean age yrs } \pm \mathrm{DS} \\
\text { (mediana)[range] }\end{array}$ & $\begin{array}{l}67.8 \pm 17.4 \\
(80)[40-94)\end{array}$ & $83.8 \pm 3.2$ & $50.7 \pm 6.4$ & \\
\hline $\begin{array}{l}\text { Indication for CE: } \\
\text { Anemia } \\
\text { Melena } \\
\text { Suspected Crohn's } d . \\
\text { Miscellanea } \\
\text { Missing }\end{array}$ & $\begin{array}{r}121(59.0) \\
37(18.0) \\
8(3.9) \\
33(16.1) \\
6(2.9)\end{array}$ & $\begin{array}{c}81(77.9) \\
18(17.3) \\
0 \\
5(4.8)\end{array}$ & $\begin{array}{c}40(42.1) \\
19(20.0) \\
8(8.4) \\
28(29.5)\end{array}$ & $\begin{array}{l}<0.001 \\
<0.001^{\wedge} \\
\mathrm{ns} \hat{\wedge} \\
n s \hat{\wedge} \\
<0.001^{\wedge}\end{array}$ \\
\hline
\end{tabular}


$p$, difference between groups by Pearson chi-square, and $\wedge$ by pairwise comparison of proportions; ns, non significant.

Table 2. Diagnostic yield of CE in both groups investigated in this study.

\begin{tabular}{|c|c|c|c|c|}
\hline & $\begin{array}{c}\text { Total } \\
(\mathrm{n}=205) \\
\mathrm{n}(\%)\end{array}$ & $\begin{array}{c}\text { Group } A \\
(\geq 80 \text { yrs, } n=106) \\
n \text { (valid \%) }\end{array}$ & $\begin{array}{c}\text { Group } B \\
\text { (40-60 yrs, } \mathrm{n}=99) \\
\text { n (valid \%) }\end{array}$ & $p$ \\
\hline $\begin{array}{l}\text { Diagnostic yield: } \\
\text { Negative } \\
\text { Angiodysplasias } \\
\text { Ulcers/erosions } \\
\text { Crohn's disease } \\
\text { Tumors } \\
\text { Miscellanea } \\
\text { Missing }\end{array}$ & $\begin{array}{c}66(32.2) \\
46(22.4) \\
37(18.0) \\
7(3.4) \\
2(1.0) \\
39(19.0) \\
8(3.9)\end{array}$ & $\begin{array}{c}30(29.4) \\
35(34.3) \\
22(21.6) \\
1(1 \%) \\
0 \\
14(13.7)\end{array}$ & $\begin{aligned} & 36(37.9) \\
11 & (11.6) \\
15 & (15.8) \\
6 & (6.3) \\
2 & (2.1) \\
25 & (26.3)\end{aligned}$ & $\begin{array}{c}{ }^{-} \\
\mathrm{ns}^{\wedge} \\
<0.001^{\wedge} \\
\mathrm{ns}^{\wedge} \\
\mathrm{ns}^{\wedge} \\
\mathrm{ns}^{\wedge} \\
<0.05^{\wedge}\end{array}$ \\
\hline
\end{tabular}

$p$, difference between groups by Person chi-square, and ^ by pairwise comparison of proportions; ns, non significant.

\section{Figures}

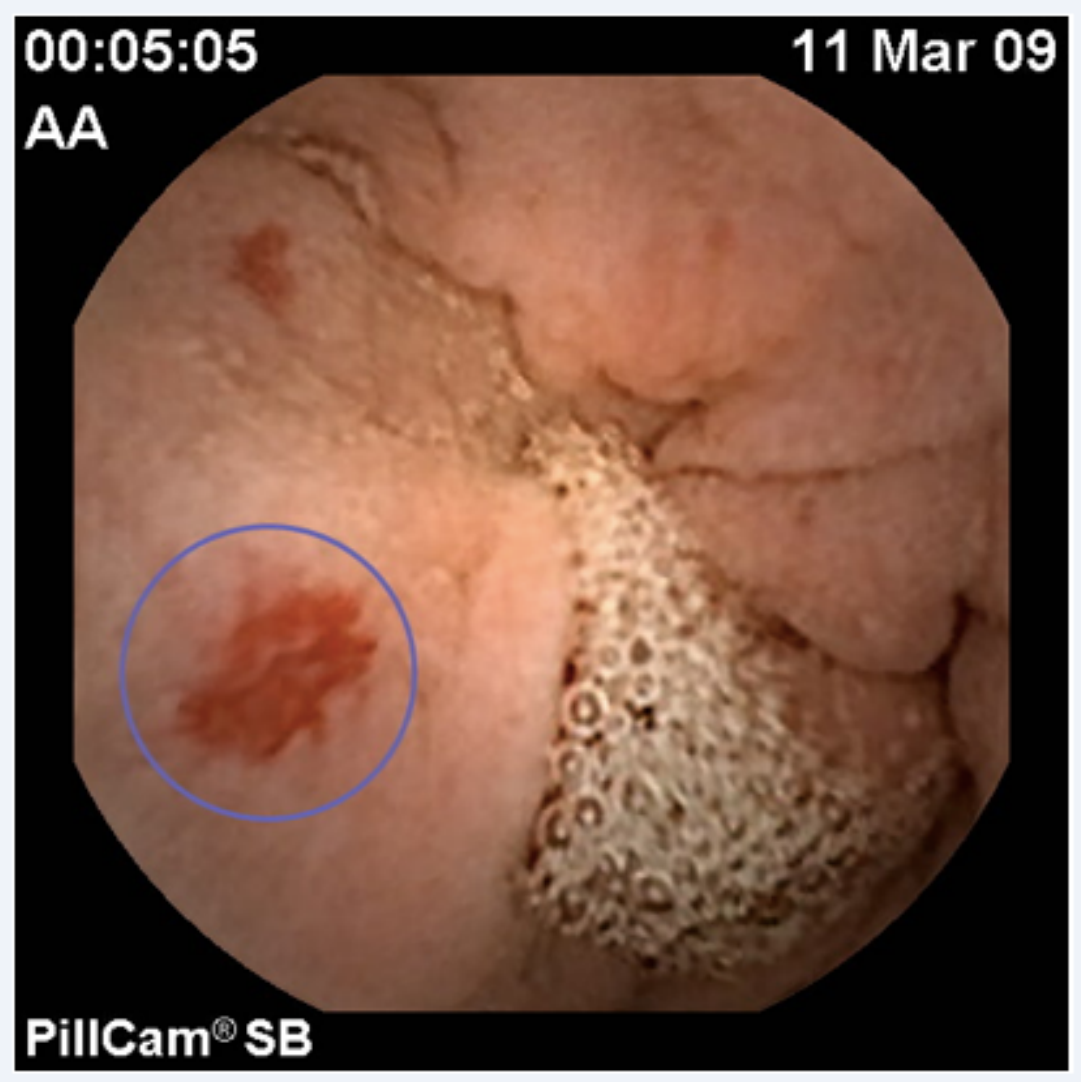

Figure 1 
Representative image of a CE exam in an 85 years old patient with a clinical history of recurrent occult bleeding. Note the evident spot (blue circle) indicative of angiodysplasia in the jejunum.

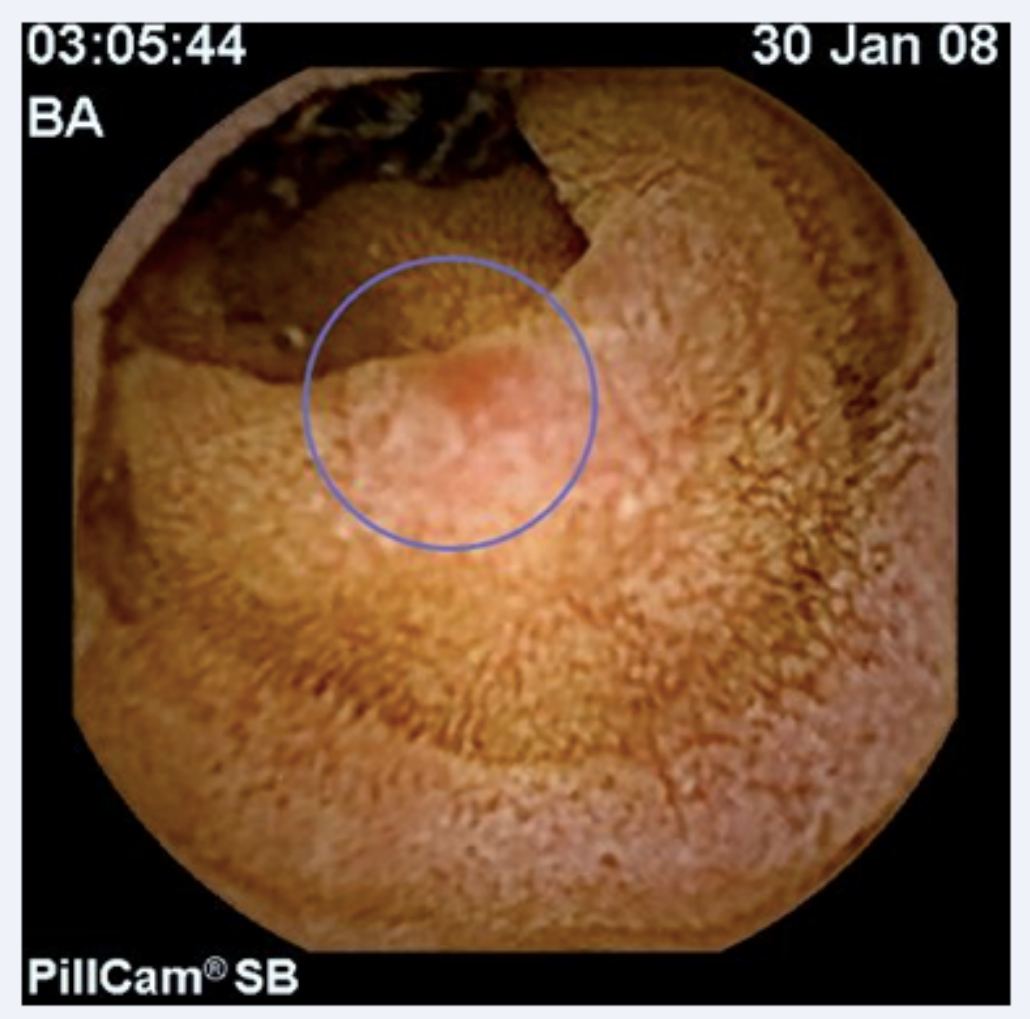

Figure 2

CE image showing an erosion (blue circle) of the jejunum in a 65 years old patient with a diagnosis of Crohn's disease. 


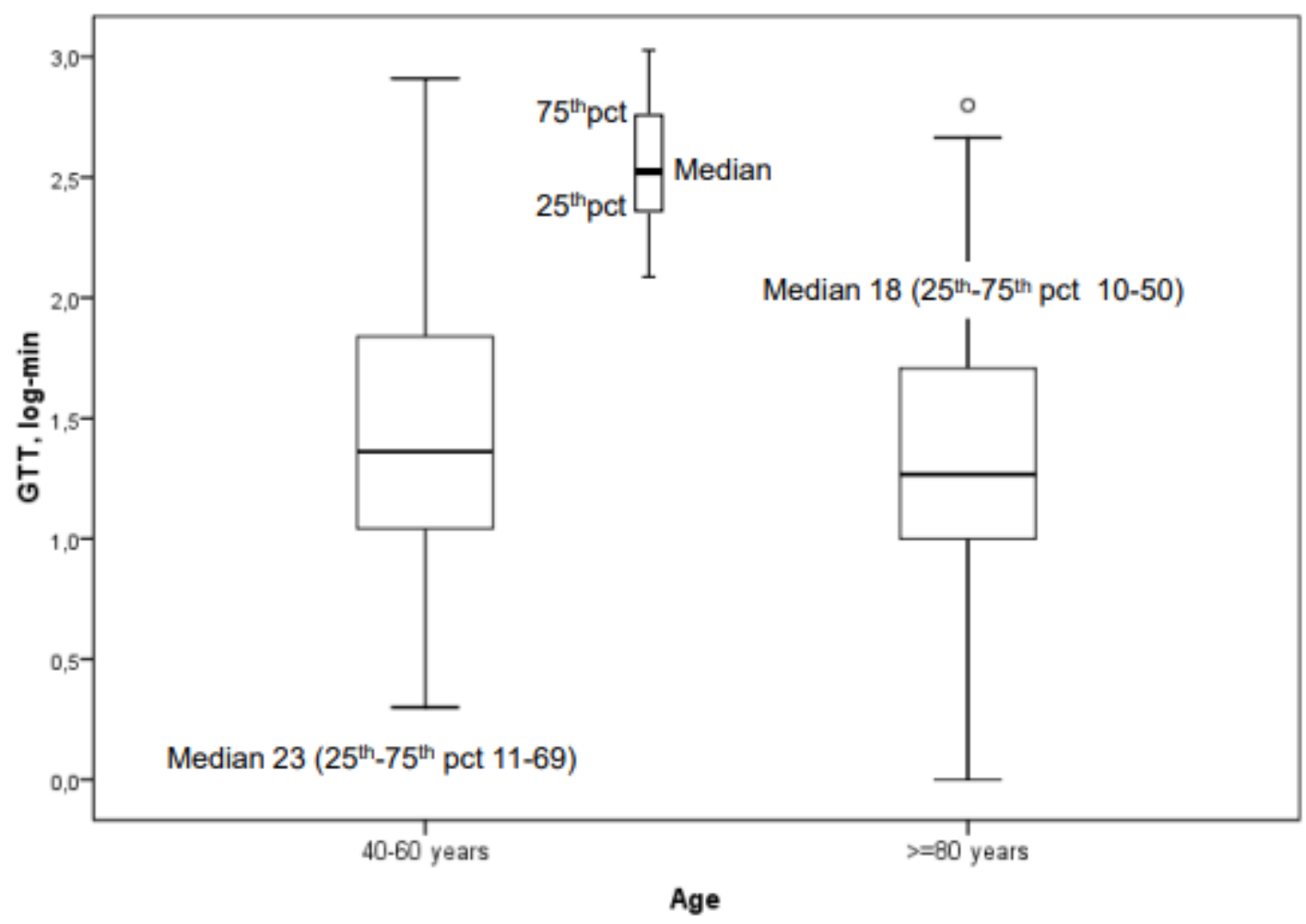

Figure 3

Bloxpot illustrating the gastric transit time which was not significantly changed in the two groups of patients under investigation.

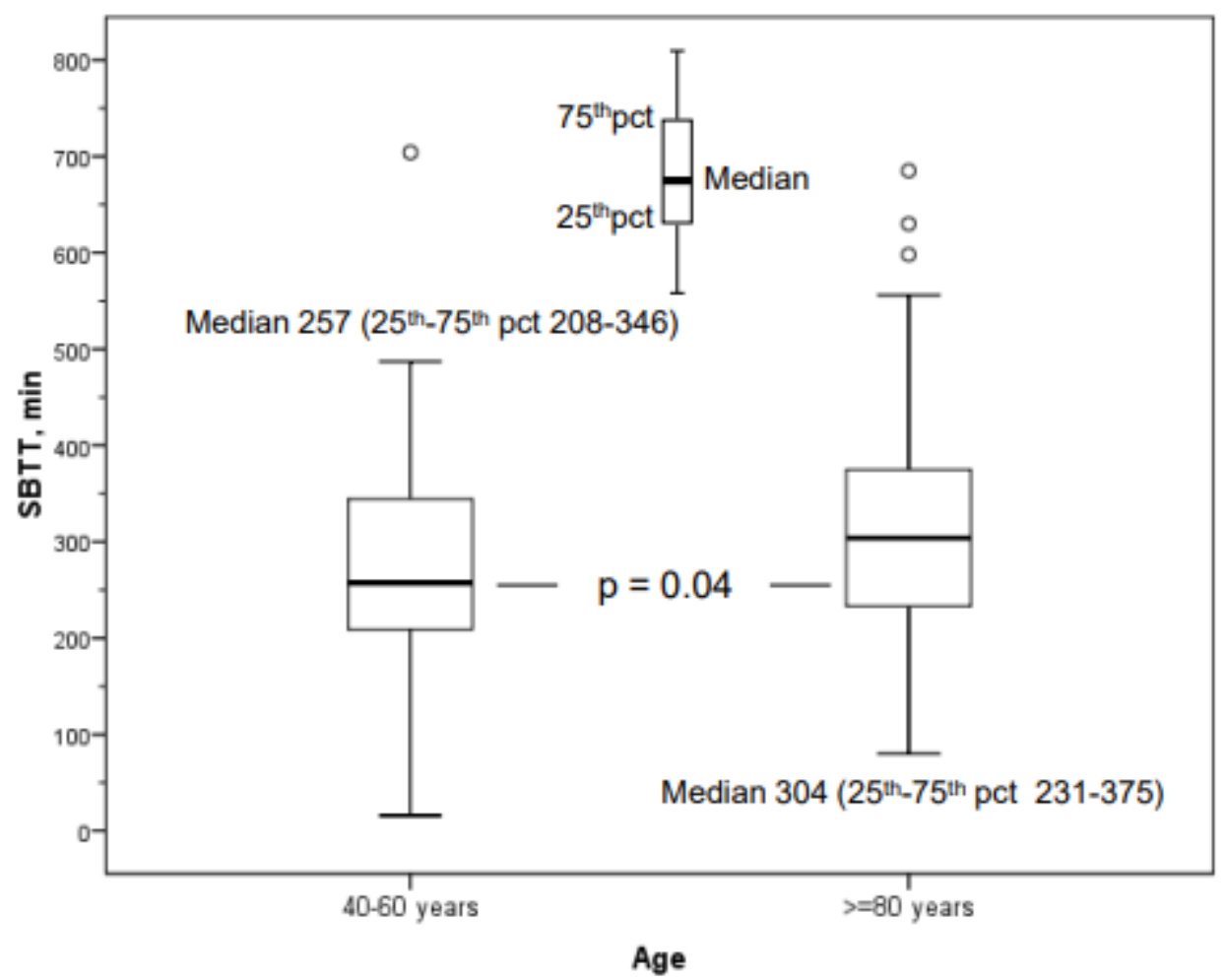

Page 16/17 
Figure 4

Bloxpot showing a statistically significant delayed small bowel transit time in the ultra-octagenuarians vs. younger patients $(p=0.04)$. 